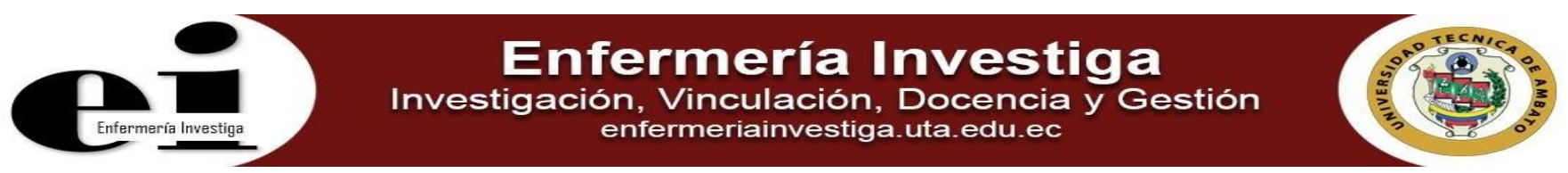

DOI: http://dx.doi.org/10.29033/enfi.v4i1.486

Editorial

\title{
Novedades metodológicas para la enseñanza de las Ciencias Biomédicas
}

Methodological innovations for the teaching of biomedical sciences

\section{Lizette Elena Leiva Suero ${ }^{1}$, Elena Vicenta Hernández Navarro ${ }^{1}$}

${ }^{1}$ Universidad Técnica de Ambato, Carrera de Medicina - GRUPO DE INVESTIGACIÓN ACADEMICA Y CIENTIFICA EN CIENCIAS BIOMÉDICAS CON PROYECCION SOCIAL K'USKIYKUY YACHAY SUNTUR - Ambato - Ecuador

Leiva LE, Hernández EV. Novedades metodológicas para la enseñanza de las Ciencias Biomédicas. Enferm Inv. 2019; 4(1):1

2477-9172 / 2550-6692 Derechos Reservados @ 2019 Universidad Técnica de Ambato, Carrera de Enfermería. Este es un artículo de acceso abierto distribuido bajo los términos de la Licencia Creative Commons, que permite uso ilimitado, distribución y reproducción en cualquier medio, siempre que la obra original es debidamente citada.

\section{Historia:}

Recibido: 15 febrero 2019 Aceptado: 15 marzo 2019

Las Ciencias Biomédicas han devenido en un campo en desarrollo para la investigación académica y científica en la Educación Superior. Como parte del perfeccionamiento curricular en las Ciencias de la Salud, se evidenció la necesidad de sustentar el desarrollo armónico de la educación en las Ciencias Básicas, con vistas a preservar su acervo teórico, los avances académicos y científicos, así como su impacto en la solución de los problemas de salud de la sociedad, desde perspectivas flexibles e innovadoras, todo lo cual contribuye a perfeccionar el proceso de enseñanza aprendizaje, para alcanzar niveles cualitativamente superiores en los aspectos cognitivos, procedimentales y actitudinales de los estudiantes de pre y posgrado.

Se consideró como bases metodológicas para el perfeccionamiento de los diseños curriculares:

1. La integración de las funciones sustantivas de la Educación Superior: academia, investigación, gestión y vinculación con la sociedad, aplicado al ámbito de las Ciencias Biomédicas.

2. La Biomedicina como ciencia y arte, con enfoque teórico - práctico, para la solución de los problemas de salud del individuo, la familia y la comunidad, desde una perspectiva biológica, psicológica y social, perfectamente inclusiva e intercultural.

3. Aplicación de los más modernos avances científico-técnicos en relación con las Ciencias de la Salud, a partir de los preceptos establecidos en las Conferencias Internacionales de Educación Superior, que garanticen una continuidad en la formación profesional de pregrado y posgrado.

4. Educación centrada en el aprendizaje del estudiante, con la incorporación de las más novedosas tecnologías de la información y las comunicaciones, la simulación médica, los más modernos laboratorios para prácticas y experimentación de los fundamentos teóricos, lo cual garantiza un nivel superior en la formación académica y científica de los profesionales.

5. Especial énfasis en la formación ética y bioética de los profesionales de la salud, que incluye atención al currículo oculto.

6. Formación metodológica que permita el desarrollo de investigaciones científicas en las Ciencias Biomédicas con adecuado rigor e impacto en los indicadores de salud.

7. Enfoque sistémico y holístico en los proyectos curriculares de pre y posgrado.

8. Estudio de pertinencia que respalde el diseño curricular con garantía de calidad en la formación profesional para la solución de los problemas de salud a nivel nacional e internacional.

9. Aplicación de los principios de la UNESCO: aprender a conocer, aprender a hacer, aprender a convivir y aprender a ser. Todo lo cual está refrendado por el objetivo 4 del Desarrollo Sostenible que aborda la educación con calidad.

Esto permitirá el desarrollo de un pensamiento científico superior por los educandos, a partir del desarrollo de competencias, habilidades y destrezas en las Ciencias Biomédicas como base para el estudio de las Ciencias Clínicas con aplicación del método científico, clínico y epidemiológico. Los contenidos estarán integrados dentro de las unidades curriculares para el desarrollo de los modos de actuación profesional a través de actividades de educación en el trabajo y desarrollo de cátedras integradoras. Facilitando el autoaprendizaje a lo largo de la vida desde perspectivas desarrolladoras. La Universidad Técnica de Ambato se inserta en los procesos de perfeccionamiento formativo en el área de posgrado, a través del desarrollo de maestrías y especialidades. 